\title{
Adsorptions of Astrazon Dye onto Granular Carbon-Silica Aerogels Synthesized from Recycle Palm-Date Pits: Kinetics, Thermodynamic and Isotherm Studies
}

\author{
Sherif A. Younis ${ }^{1,21}$, Yasser M. Moustafa ${ }^{1,2}$; Mohamed R. Selim ${ }^{3}$; Ahmed Z. Sayed ${ }^{3}$; Yousef A. Selim ${ }^{3}$ \\ ${ }^{1}$ Analysis and Evaluation Department, Egyptian Petroleum research Institute, 11727 Nasr City, Cairo, Egypt. \\ ${ }^{2}$ Liquid chromatography unit, Central laboratories, Egyptian Petroleum research Institute, 11727 Nasr City, \\ Cairo, Egypt. \\ ${ }^{3}$ Chemistry Department, Faculty of Science (Boys), Al-Azhar University, 11884, Nasr City, Cairo, Egypt. \\ ABSTRACT
}

In this work, an environmental friendly management process was achieved to solve solid and liquid hazardous contaminants in our environment. In this case, a granular carbon (gAC) sorbent impregnated with $\mathrm{SiO}_{2}$ aerogels as composite $\left(\mathrm{gAC}_{\mathrm{SiO}}\right)$ was synthesized from the rceycling of palm-date pits solid waste products to remediate wastewater solution contaminated with Astrazon pink FG cationic dye. The Astrazon dye adsorption onto the $\mathrm{gAC} / \mathrm{SiO} 2 \mathrm{was}$ investigated by compared to $\mathrm{gAC}$ sorbent alone using a batch system with respect to initial dye concentration, $\mathrm{pH}$, contact time, solution temperature and adsorbents dosage. It was found the amount of adsorbed dye was strongly depended on $\mathrm{pH}$ with low significant important of temperatures levels range from 298 to $318 \mathrm{~K}$. The prepared $\mathrm{gAC} / \mathrm{SiO}_{2}$ aerogels composite exhibits high efficiency for Astrazon dye adsorption by approximately 1.5 times than that of gAC alone. The equilibrium adsorption states could be achieved in $6 \mathrm{~h}$ when using $\mathrm{gAC} / \mathrm{SiO}_{2}$ comparable to $12 \mathrm{~h}$ by $\mathrm{gAC}$ for the different initial dye concentrations. The adsorption kinetics were found to best described by the pseudo-second order model (PSOM) and pseudo-first order (PFOM) kinetic models respectively, when using $\mathrm{gAC}$ and $\mathrm{gAC} / \mathrm{SiO}_{2}$ sorbents, and poorest-fit with Elvoich equation as confirmed by nonlinear chi-square error test and determination coefficient values. The equilibrium isotherm study indicated that dye adsorption data were analyzed and fitted well by the nonlinear expressions of both Langmuir and Langmuir-Freundlich models compared to Freundlich, Temkin and Redlich-Peterson models. The maximum monolayer Astrazon dye adsorption was estimated to be 185.59 and $256.02 \mu \mathrm{mol} / \mathrm{g}$ by $\mathrm{gAC}$ and $\mathrm{gAC} \mathrm{SiO}$ adsorbents. The positive values of the enthalpy $\left(\Delta \mathrm{H}^{\circ}\right)$ and negative Gibbs free energy $\left(\Delta \mathrm{G}^{\circ}\right)$ changes indicate an endothermic as well as feasible and spontaneous nature of the adsorption process respectively.

\section{Keywords}

Granular carbon-silica aerogels; Astrazon pink FG dye; adsorption; kinetics; thermodynamic; equilibrium isotherm modeling.

\section{INTRODUCTION}

Water pollution is identified as one of the major concern because of its threats to many forms of life. Synthetic dyes are organic compounds exhibit considerable structural diversity, which consisting of chromophores (aryl rings that have delocalized electron and responsible for dye color) and auxochromes (responsible for the intensity of the color) [1]. The presence of ionizing groups, such as $-\mathrm{NH}_{3},-\mathrm{COOH},-\mathrm{HSO}_{3},-\mathrm{OH}$, known as auxochromes results in a much stronger alternation of the maximum absorption of the compound and provides a bonding affinity [1]. Colored wastewater arises as a direct result of the production of organic dyes and also as a consequence of its use in different industries such as leather, textile, plastics, paper, etc. According to the Color Index (C.I.), currently more than 10,000 various types of dyes are synthesized and available in the world. Due to the good solubility of the synthetic dyes, organic dyes are common water pollutants, even in trace quantities, and they are considered to be the most recalcitrant identified wastewater pollutants to biodegradation by native microbial habitants $[2,3]$. As a fact that $2-3 \%$ of dyes produced annually are discharged in wastewater effluents from manufacturing operations, while $10-12 \%$ was discharged from textile and associated industries, which give an indication of the scale of the problem [1]. Since dyes are stable, recalcitrant, and even potentially toxic, their discharge into the water environment poses serious environmental, aesthetical and health problems $[1,4,5]$. Thus, from an environmental and health point of view, the treatment of aqueous effluents containing soluble organic dyes is of great significance followed by secure disposal. To date, many techniques have been explored, such as chemical precipitation and oxidation, ion exchange, biological treatment, coagulation, reverse osmosis, photocatalytic degradation, ozonation and solvent extraction and adsorption, to remove the dyestuffs contaminants in the wastewater effluents [2-4,6].

Adsorption at the solid-liquid interface offering significant advantages over other treatment processes due to its merits of simplicity and automation, scale up construction, high efficiency and allowing the recovery of adsorbate especially from operational economic and an environmental point of view [2,4,5]. Many types of adsorbents have been developed and reported, such as industrial by-products, magnetic nanomaterials, zeolites, activated carbons, metal oxides nanoparticles, clays, agricultural wastes, metal-organic frameworks and polymeric materials [4,7-9]. Recently, granular activated carbon (gAC) has been regarded by the numerous literature as the best available adsorbent for removing many organic pollutants, e.g. pharmaceuticals, and industrial chemicals, from various types of water effluents [10-12]. But, the problems with the gAC adsorbent has been identified as low adsorption capacity for soluble organic pollutants and its high costs of

${ }^{1}$ Correspondence: Sherif A. Younis

E-mail: sherifali_r@yahoo.com; sherifali@epri.sci.eg ; Tel.: (+201) 2288774 58; Fax: (+202) 22747433 


\section{ISSN $2321-807 x$ \\ Volume $12 \mathrm{Number} 10$ \\ Journal of Advances in Chemistry}

manufacturing due to the high cost resulting from the use of non-renewable and expensive starting materials, such as coal $[10,11,13]$. In order to improve the efficiency of the gAC adsorption processes to treat a large quantity of effluents in a large scale, it is necessary to develop cheaper and easily available gAC adsorbents with high adsorption capacities. Thus, several researchers now are attempting to produce cheaper, more effective and environmentally friendly activated carbons from renewable and cheap precursors, for example from wastes and agricultural by-products [14-16]. In addition, recent studies focused on the use of alumina, silica, and titania sol-gel materials as adsorbents for pollutants from wastewater [17], but very few literatures reported the applicability of the porous silica aerogels for the treatment of organic dyes contaminated wastewater. Therefore, surface functionalization of gAC with silica aerogels are among the most influencing affected factors that could be used to enhance the adsorption capacity of the gAC for commercial application.

The objectives of this work were to prepare granular activated carbon from palm-date pits using chemical activation with $\mathrm{H}_{3} \mathrm{PO}_{4}$ followed by microwave thermal carbonization. After that, a cheap granular carbon based silica aerogels composite $\left(\mathrm{gAC} / \mathrm{SiO}_{2}\right)$ as an unconventional adsorbent was synthesized from sodium metasilicate precursor for decolourising water solutions contaminated with organic dyestuffs such as Astrzon pink FG dye model compound. In this context, the effects of contact time, initial dye concentration, solution temperature, adsorbent dose and solution $\mathrm{pH}$ on the adsorption of Astrazon dye onto $\mathrm{gAC}$ and $\mathrm{gAC} / \mathrm{SiO}_{2}$ were investigated in detailed. As well as the equilibrium, kinetic and thermodynamic data of the adsorption systems of the dye onto the fabricated adsorbents were studied using nonlinear regression expressions. The adequacy and the suitability of the nonlinear mathematical kinetic and isotherm models and their validation to predict the experimental adsorption results were further assessed using error statistic provided by using the solver add-in with Microsoft Excel@2013, MINITAB (v.17) and IBM-SPSS (v. 21) statistical package for the verification of the results obtained.

\section{Experimental procedure}

\section{II.1. Materials}

Palm-date pits collected from palm tree plantations in the City of Sohag, Egypt and Astrazon pink FG dye (adsorbate) was purchased from TCl (Japan); Fig. 1. Sodium metasilicate pentahydrate $\left(\mathrm{Na}_{2} \mathrm{SiO}_{3} .5 \mathrm{H}_{2} \mathrm{O}>95 \%\right)$, ethanol $(\mathrm{EtOH}>95 \%)$, $\mathrm{NaOH}$ pellets (99\%), $\mathrm{HCl}(36 \%)$ and $\mathrm{NH}_{3} \cdot \mathrm{H}_{2} \mathrm{O}(36 \%)$ were purchased from Sigma-Aldrech and Merck (USA). Deionized water $\left(\mathrm{DI}-\mathrm{H}_{2} \mathrm{O}\right)$ used to prepare at Liquid Chromatography unit in Central Laboratories at the Egyptian Petroleum Research Institute.

Fig.1. Astrazon Pink FG dye

\section{II.2. Synthesis of granular carbon-silica aerogels $\left(\mathrm{gAC} / \mathrm{SiO}_{2}\right)$ composite adsorbent}

In this experiment, granular activated carbon ( $\mathrm{gAC}$ ) was synthesized from the seeds of palm-date pits. The palm seeds as collected were washed with hot $\mathrm{DI}-\mathrm{H}_{2} \mathrm{O}$ to remove dust and impurities, then dried at $393 \mathrm{~K}$ and mechanically ground in a grinder (Perten, model LM 3310, USA). The sieved palm seeds of $0.5-2 \mathrm{~mm}$ were chemically activated by 40 wt\% phosphoric acid for $6 \mathrm{~h}$ at $358 \mathrm{~K}$. After that, the chemically activated palm seeds were dried for $48 \mathrm{~h}$ at $383 \mathrm{~K}$. Then, the thermal activation step was carried out using a quartz reactor inside a conventional muffle furnace set at $\approx 1000^{\circ} \mathrm{K}$ for about $2 \mathrm{~h}$. The resultant gAC was cooled to room temperature, and washed with $0.1 \mathrm{~N}$ hydrochloric acid and then by hot $\mathrm{DI}-\mathrm{H}_{2} \mathrm{O}$ until near neutral $\mathrm{pH}$. The washed $\mathrm{gAC}$ was dried at $378 \mathrm{~K}$ for $24 \mathrm{~h}$ and stored in a tightly closed plastic container for further use.

Granular AC-silica ( $\mathrm{gAC} / \mathrm{SiO}_{2}$ ) aerogels composites were synthesized by a single sol-gel method. In a glass vessel, $1 \mathrm{M}$ of sodium metasilicate in a solution mixture of $\mathrm{EtOH}$ and $\mathrm{DI}-\mathrm{H}_{2} \mathrm{O}(1: 1 \mathrm{vol} \%)$ was heated to $333 \mathrm{~K}$ under vigorous stirring for $1 \mathrm{~h}$. Then the silicate sol with or without $\mathrm{gAC}$ was transferred to an ultrasonic bath $(60 \mathrm{~Hz})$ and $0.05 \mathrm{~N} \mathrm{HCl}$ was added until the $\mathrm{pH}$ reaching $\mathrm{pH} 6 \sim 6.5$, and then the reaction proceeded for $3 \mathrm{~h}$. After that, equal volume of $\mathrm{DI}-\mathrm{H}_{2} \mathrm{O}$ was added to age the gelatin obtained for $12 \mathrm{~h}$. Mechanical solvent exchange of the gel to granules was proceeded by agitated twice with $\mathrm{EtOH}$ then $n$-hexane at $300 \mathrm{rpm}$ stirring for $24 \mathrm{~h}$ in a water bath set at $318 \mathrm{~K}$. Finally, the resultant gel was dried in ambient pressure at $373 \mathrm{~K}$ for $4 \mathrm{~h}$ to get silica $\left(\mathrm{SiO}_{2}\right)$ aerogels or granular $\mathrm{AC}$ - silica $(\mathrm{gAC} / \mathrm{SiO})$ aerogels composite, which stored until further use. Based on experimental calculation, the products yielded were determined as $19 \%$ silica aerogels as an end product resulting from the hydrolysis of sodium metasilicate precursor and the g- $\mathrm{AC}: \mathrm{SiO}_{2}$ aerogels in composite sample was found as 1:0.8.

\section{II.3. Adsorption procedures}

Astrazon adsorption experiments were conducted in a $100 \mathrm{~mL}$ glass flask, each of which contained $30 \mathrm{~mL}$ contaminated aqueous solution. An amount of either $\mathrm{gAc}$ or $\mathrm{gAC} / \mathrm{SiO}_{2}$ composite $(5 \mathrm{~g} / \mathrm{L})$ was added to each flask and shaken in a thermometer water bath fixed at $300 \mathrm{rpm} / \mathrm{min}$ and room temperature for $24 \mathrm{~h}$ to ensure equilibrium was reached. The effect of several variables of contact time (1-24 h), initial dye concentrations (125-650 $\mu \mathrm{mol})$, solution temperature (298 $318 \mathrm{~K})$, adsorbent dose (1-10 g/L), and $\mathrm{pH}(3-10)$ were further studied. To study the effect of initial dye concentrations on the Astrazon uptake, the initial $\mathrm{pH}$ of the solutions was originally without any $\mathrm{pH}$ adjustment whereas the adsorbent

4425 | P a g e 


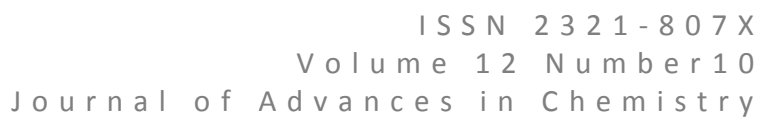

dosage, agitation speed were remained constant, while the solution temperatures vary between 298 to $318^{\circ} \mathrm{K}$. Whereas, to investigate the effect of adsorbent dose $(1-10 \mathrm{~g} / \mathrm{L})$ and $\mathrm{pH}(3-10)$, the initial dye concentration and temperature variables were set at $650 \mu \mathrm{mol}$ and $318 \mathrm{~K}$ respectively at agitation speed of $300 \mathrm{rpm} / \mathrm{min}$.

After the adsorption process, the flask samples were taken out and filtered to remove residual adsorbent. The remaining amount of Astrazon dye in water solutions were determined using a double-beam UV-Visible spectrophotometer (Perkin Elmer) at $520 \mathrm{~nm}$. The adsorption efficiency (\%R) and adsorbed dye per unit mass of $\mathrm{gAC}$ or $\mathrm{gAC} / \mathrm{SiO}_{2}$ aerogels, $\mathrm{q}_{\mathrm{e}}(\mu \mathrm{mol} / \mathrm{g})$, was calculated according to Eq. (1 and 2). All the experiments were carried out in duplicate and mean values are presented.

$$
\begin{aligned}
& \% \mathrm{R}=\left(C_{0}-C_{t}\right) \times \frac{100}{C_{0}} \\
& q_{e}=\left(C_{0}-C_{\theta}\right) \times \frac{V}{W}
\end{aligned}
$$

Where $C_{0}, C_{t}$ and $C_{e}(\mu \mathrm{mol})$ are the liquid-phase of Astrazon dye concentrations at initial, time (t) and equilibrium respectively; $\mathrm{V}(\mathrm{L})$ is the water volume; $\mathrm{W}(\mathrm{g})$ is the mass of adsorbent used.

For batch kinetic studies, the same procedure was followed but aliquot samples were taken at different time intervals ( 1 $24 \mathrm{~h}$ ) to calculate the amount of adsorbed dye concentrations and against times at two temperatures ranges of 298 and $318^{\circ} \mathrm{K}$. The equilibrium studies of adsorbed Astrazon dye were established after 12 and $6 \mathrm{~h}$, respectively when using gAC and $\mathrm{gAC} / \mathrm{SiO}_{2}$ adsorbents. The equilibrium isotherm studies were investigated at the initial dye concentrations ranges from $125 \mu \mathrm{mol}$ to $1000 \mu \mathrm{mol}$. The experimental results were also evaluated by various adsorption isotherms incorporating Langmuir, Freundlich, Temkin, Redlich-Peterson, and Langmuir-Freundlich isotherms and were simulated with different kinetic models including pseudo first, pseudo second order, Elovich, and intraparticle diffusion models.

To study thermodynamic experiments, flasks containing $1 \mathrm{~g} / \mathrm{L}$ of each adsorbent suspended in contaminated water solution with Astrazon dye at initial concentrations of $125 \mu \mathrm{mol}$ and $650 \mu \mathrm{mol}$ were agitated in an isothermal water bath shaker at different temperatures of $298,303,310$ and $318^{\circ} \mathrm{K}$. The residual dye concentrations were detected by a doublebeam UV-Visible spectrophotometer after 12 and $6 \mathrm{~h}$ respectively, to calculate the adsorbed capacity of the gAC and $\mathrm{gAC} / \mathrm{SiO}_{2}$ adsorbents.

\section{II.4. Statistical results evaluation}

The adequacy of the nonlinear mathematical kinetic and isotherm models and their validation were assessed using error statistic $s$ method by a nonlinear chi-square error $\left(X^{2}\right)$ test to reflect the suitability of the mathematical models to predict the adsorption responses [22]. The statistical validation and error studies were checked by using the solver add-in with Microsoft Excel@2013, MINITAB (v.17) and IBM-SPSS (v. 21) statistical package for the verification of the results obtained.

$$
X^{2}=\sum_{i=1}^{N}\left|\frac{\mathbb{V}_{\text {axpi }}-Y_{p r v d i} i}{Y_{\text {axpi }}}\right|^{2}
$$

Where $Y_{\text {pred i }}$ and $Y_{\exp i}$ are the model predicted and experimental response values and $\mathrm{N}$ is the number of experimental runs. Statistical comparison of the adsorption results were also evaluated using different descriptive statics including a parametric two-sample (unpaired) t-test in accordance with the analysis of variance (ANOVA) at a probability level of 0.05 .

\section{Results and Discussion}

\section{III.1. Effect of adsorption parameters on the uptake rate of the Astrazon pink FG dye}

The adsorption uptake rate of Astrazon pink FG was investigated using the adsorbed dye concentrations on the gAC and $\mathrm{gAC} / \mathrm{SiO}_{2}$ aerogels adsorbents as a function of contact time $(\approx 1-24 \mathrm{~h})$, initial dye concentrations $(\approx 125-650 \mu \mathrm{mol})$, temperatures $(\approx 298-318 \mathrm{~K}), \mathrm{pH}$ of solution $(\approx 3-10)$ and adsorbent dose $(\approx 1-10 \mathrm{~g} / \mathrm{l})$.

\section{III.1.1. Effect of contact time and solution temperature}

The contact time in liquid-solid interaction between dissolved dye pollutant and solid adsorbent surface is of significant importance in the treatment of wastewater by adsorption [23]. To determine the conditions at which the adsorption equilibrium attained, the adsorption rate of the basic Astrazon dye onto $\mathrm{gAC}$ and $\mathrm{gAC} / \mathrm{SiO}_{2}$ aerogels adsorbents was studied for initial dye concentration of 125 to $650 \mu \mathrm{mol}$ at temperatures of 298 and $318{ }^{\circ} \mathrm{K}$ as a function of contact time (1 $-24 \mathrm{~h}$ ). As seen in Fig. 2, the adsorption processes are quite rapid and consisted of two stages; a primary rapid stage at which $>64 \%$ and $>90 \%$ of the dye within the first $12 \mathrm{~h}$ to $6 \mathrm{~h}$ of initial contact by $\mathrm{gAC}$ and $\mathrm{gAC} / \mathrm{SiO}_{2}$ and thereafter, a secondary equilibrium stage were retained. Astrazon pink FG dye solutions were kept in contact with both adsorbents for $24 \mathrm{~h}$ although no significant variation in $q_{e}(\mu \mathrm{mol} / \mathrm{g})$ was detected with smooth and continuous curves using $\mathrm{gAC}$ and $\mathrm{gAC} / \mathrm{SiO}_{2}$ sorbents after $12 \mathrm{~h}$ and $6 \mathrm{~h}$ of initial contact leading to saturation at the studied variables of temperatures and dye concentrations. The calculated $q_{t}$ was increased by $8.3 \pm 0.86 \%$ to $4.3 \pm 0.67 \%$ using gAC and $\mathrm{gAC} / \mathrm{SiO}_{2}$ adsorbents during the second stage of adsorption as initial concentration increased from 125 to $650 \mu \mathrm{mol}$ at the studied temperatures. These curves indicate the possible monolayer coverage of Astrazon dye on the surface of $\mathrm{gAC}$ and $\mathrm{gAC} / \mathrm{SiO} 2 \mathrm{adsorbents}$.

4426 | P a g e 


\section{ISSN $2321-807 x$ \\ Volume $12 \mathrm{Number} 10$ \\ Journal of Advances in Chemistry}

Thus it was assumed that after 6 and $12 \mathrm{~h}$ of contact time respectively, using $\mathrm{gAC}$ and $\mathrm{gAC} / \mathrm{SiO}_{2}$, a steady-state of approximation and a quasi-equilibrium situation was accepted (Fig. 2a). A rapid uptake of dye by $\mathrm{gAC} / \mathrm{SiO}_{2}$ aerogels and establishment of equilibrium in a short period of $6 \mathrm{~h}$ compared to gAC adsorbent signify the efficacy of $\mathrm{gAC} / \mathrm{SiO} 2 \mathrm{aerogels}$ for its use in textile wastewater treatment. In physical adsorption, most of the adsorbate species are adsorbed within a short interval of contact time, however, strong chemical adsorption binding of the dye with adsorbents requires a longer time of interaction for the attainment of equilibrium [23]. Available adsorption experiments in literature reveal that the rate of uptake of adsorbate species is almost fast at the initial stages of the contact period, and thereafter, it becomes slower near the equilibrium and in between these two stages, the rate is found nearly constant $[5,23,24,22]$. Because of the fact that a large number of free vacant sites are available on the sorbents surface for dye adsorption during the first stage, and after a time lapse, the remaining vacant surface sites are difficult to be occupied due to repulsive forces between the adsorbed dye molecules on the solid surface and bulk solution phase [5,23,22]. It found also that the amount of adsorbate per unit mass adsorbent $\left(q_{e}, \mu \mathrm{mol} / \mathrm{g}\right)$ increased with the increase of an initial dye concentration from 125 to $650 \mu \mathrm{mol}$ by either $\mathrm{gAC}$ or $\mathrm{gAC} / \mathrm{SiO}_{2}$ aerogels (Fig. 2a). Such phenomenon may be due to increasing the mass transfer driving force and therefore the rate at which dye molecules pass from the bulk water solutions to the adsorbent surface increase, resulting higher dye adsorption uptake[3,23,22].

In addition, the experimental results in Fig. (2a) showed that increasing temperature from $298 \mathrm{~K}$ to $318 \mathrm{~K}$ has no significant effect on the equilibrium capacity of Astrazon dye by both adsorbents on the studied range of dye concentrations. The adsorption capacities of Astrazon dye by adsorption on gAC increases from 29.2 to $30.6 \mu \mathrm{mol} / \mathrm{g}$, 82.1 to $88.9 \mu \mathrm{mol} / \mathrm{g}$, and 125.7 to $134.4 \mu \mathrm{mol} / \mathrm{g}$ and from 36.9 to $37.3 \mu \mathrm{mol} / \mathrm{g}, 111.4$ to $113.5 \mu \mathrm{mol} / \mathrm{g}$, and 185.7 to $187.4 \mu \mathrm{mol} / \mathrm{g}$ using $\mathrm{gAC} / \mathrm{SiO}_{2}$ adsorbent when temperature increases from 298 to $318^{\circ} \mathrm{K}$ at $C_{0}$ of 125,380 and $650 \mu$ mol, respectively. This indicating the adsorption process is endothermic and mainly physical adsorption on the adsorbents surfaces with no intraparticle-diffusion of the dye molecules across the internal pores of the adsorbents particles. The experimental results obtained further confirmed by statistical analysis of the student test "t-test" and Fischer's " $F$ " test at $95 \%$ confidence level of $p<0.05$ using SPSS v.21 software (Fig. 2b). At $95 \%$ confidence level $(p<0.5)$, the temperature independently of the Astrazon adsorbed amount in our case $\left(298\right.$ and $\left.318^{\circ} \mathrm{K}\right)$ using $\mathrm{gAC}$ and $\mathrm{gAC} / \mathrm{SiO}_{2}$ adsorbents reflected by a very low $\mathrm{t}$ value of $\approx 0.370$ to $0.804<t$-critical 2.201 and Fischer's " $F$ " values of 0.137 to $0.72<$ critical $F$-value 2.24 at $p$-values ranged from 0.413 to $0.718>p \approx 0.05$. The compared statistical t- test and one way analysis of variance (ANOVA) including $F$ - and $p$-values between temperatures being studied revealed that there are no significant statistical differences in the adsorption capacities towards Astrazon dye by both sorbents. Such insignificant adsorption dependence on temperature may results on significantly reduced of the overall diffusion coefficient and the large surface-adsorption resistance due to the adsorbed dyes within a short time of contact. On the other hand, the paired-t-test implied that there were a high adsorption selectivity for $\mathrm{gAC} / \mathrm{SiO}_{2}$ towards Astrazon dye than that by using $\mathrm{gAC}$ alone with paired-t-values respectively of $8.35,12.77$, and 15.81 with $p<0.001$ at 125,380 and $650 \mu \mathrm{mol}$ initial Astrazon concentrations (Fig. 2b). In fact, a possible favoured mechanism of interaction is the electrostatic interaction between the hydroxyl and carboxylic end groups of the $\mathrm{gAC}$ and $\mathrm{gAC} / \mathrm{SiO}_{2}$ adsorbents and the cationic group $\left(\mathrm{N}^{+}\right)$in the Astrazon dye molecules could be a ratecontrolling in our study.

4427 | P a g e 
(a)

다시이 @198 K

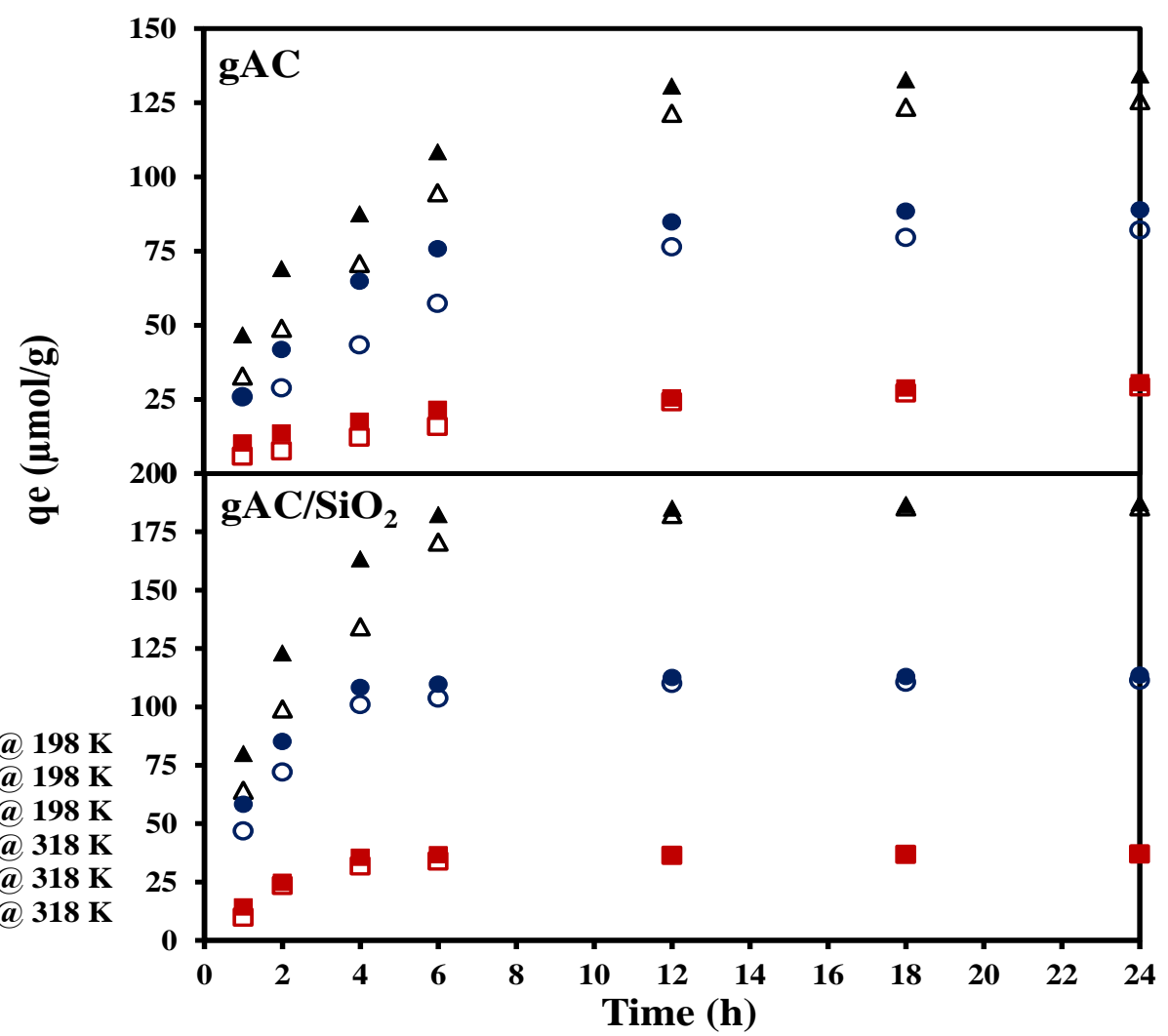

○ $350 \mu \mathrm{mol}$

$\Delta 650 \mu \mathrm{mol} @ 198 \mathrm{~K}$

- $125 \mu \mathrm{mol} @ 318 \mathrm{~K}$

- $350 \mu \mathrm{mol} @ 318$ K

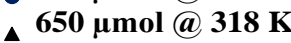

\section{Time (h)}

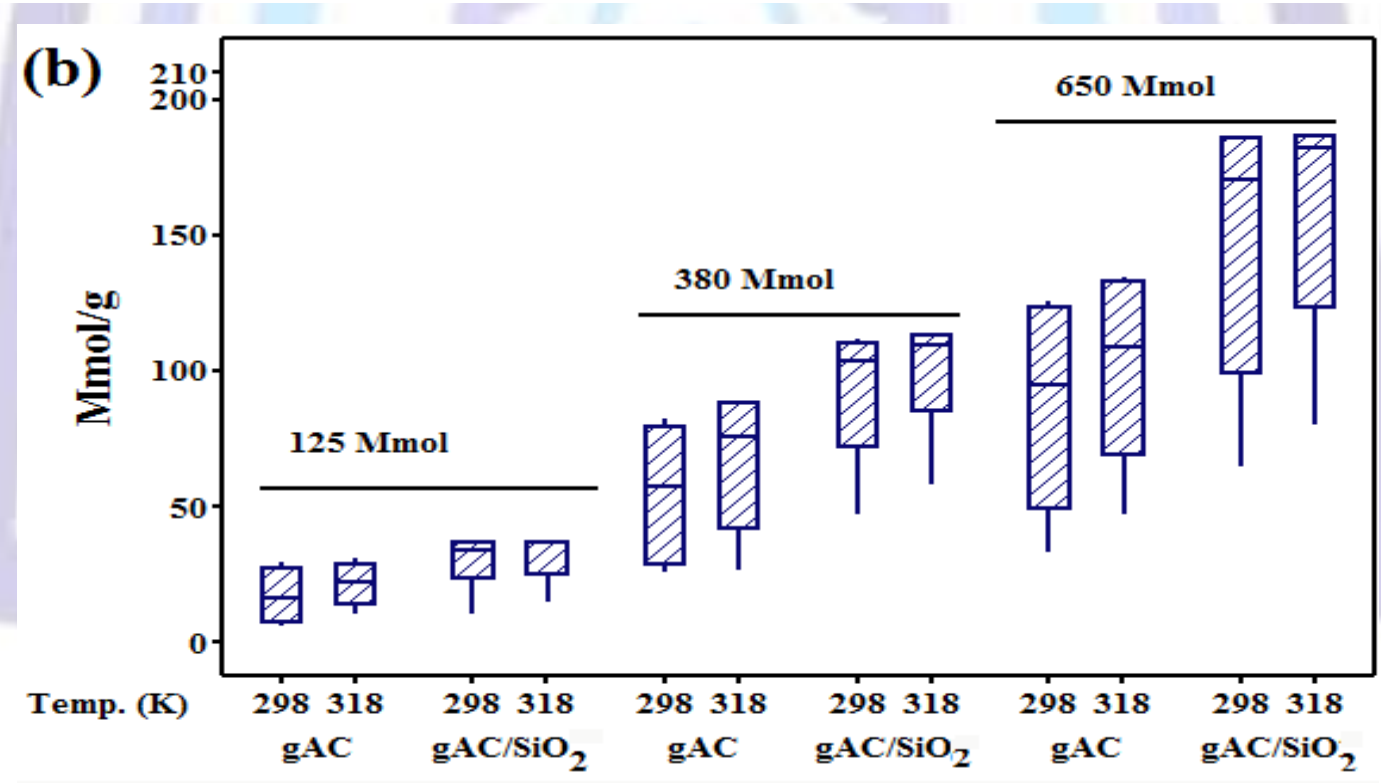

Fig. 2: Effect of initial dye concentrations and temperatures on the equilibrium adsorbed amount of astrazon pink $\mathrm{FG}$ dye using $\mathrm{gAC}$ and $\mathrm{gAC} / \mathrm{SiO}_{2}$ sorbents (a) as a function of contact time and (b) Box-plot statistic graph.

\section{III.1.2. Effect of $\mathrm{pH}$ and adsorbent dosage}

The effect of the adsorbent dose and solution pH on Astrazon pink FG dye was simultaneously studied on both gAC and $\mathrm{gAC} / \mathrm{SiO}_{2}$ adsorbents. The $\mathrm{pH}$ has an important effect on dye adsorption since the $\mathrm{pH}$ of the solution will control the magnitude of the net charges on both dye adsorbate and adsorbent surfaces and consequently affect the adsorption mechanism. As a result the rate of Astrazon dye adsorption should vary with pH change of an aqueous solution as well as adsorbent surface type. Fig. 3 reflects the influence of solution $\mathrm{pH}$ on the adsorbed amount of Astrazon dye ( $\mu \mathrm{mol} / \mathrm{g})$ by $\mathrm{gAC}$ and $\mathrm{gAC} / \mathrm{SiO}_{2}$ adsorbents in the $\mathrm{pH}$ range from 3.0 to 10.0 at $1 \mathrm{~g} / \mathrm{l}$ adsorbent dose. As seen, the adsorption capacity $(\mu \mathrm{mol} / \mathrm{g})$ of Astrazon dye onto $\mathrm{gAC}$ adsorbent showed an increase with $\mathrm{pH}$ from 3.0 to 7.0 and remains approximately 
constant from 7.0 to 9.0 , then decrease again at $\mathrm{pH} 10$. By using $\mathrm{gAC} / \mathrm{SiO}_{2}$ adsorbent, as the inverse relationship with $\mathrm{pH}$ was observed, where the maximum adsorption capacity was recorded at acidic $\mathrm{pH}<7$.

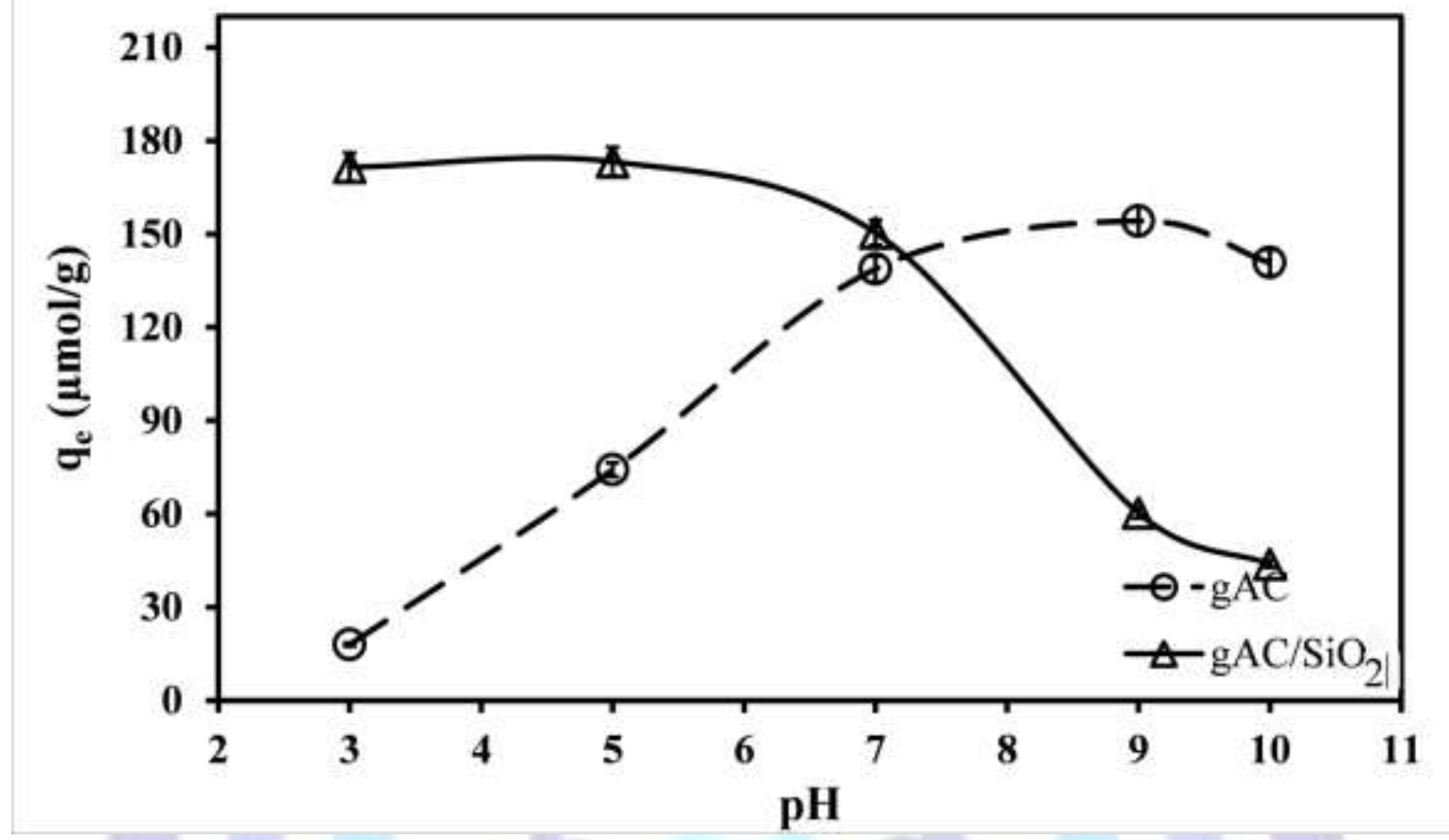

Fig. 3: Effect of pH (3-10) on the adsorbed amount of astrazon dye using $1 \mathrm{~g} / \mathrm{L} \mathrm{gAC}$ and $\mathrm{gAC} / \mathrm{SiO}_{2}$ adsorbents.

Further investigation, Fig. 4 represents the effect of the solution $\mathrm{pH}$ on the $q_{e}(\mu \mathrm{mol} / \mathrm{g})$ of Astrazon dye at different dose of $\mathrm{gAC}$ and a $\mathrm{gAC} / \mathrm{SiO}_{2}$ adsorbents to find out the minimum dosage and preferable $\mathrm{pH}$ level for the maximum Astrazon dye uptake. From Fig. 4, it can be observed that the adsorbed amount of Astrazon $(\mu \mathrm{mol} / \mathrm{g})$ increased with decreasing both adsorbent doses. In addition, the maximum adsorption capacities were recorded at alkaline $\mathrm{pH}$ for $\mathrm{gAC}$ and low acidic to neutral $\mathrm{pH}$ when using $\mathrm{gAC} / \mathrm{SiO}_{2}$ adsorbent. Therefore, the favorable adsorption of the cationic Astrazon dye on both adsorbents could be obtained at relatively low pH (in the range of $5.0-7.0$ ). This may be attributed to the enhancement of an electrostatic interactions between the positive amine groups $\left(\mathrm{N}^{+}\right)$of the Astrazon dye and the hydroxyl and carboxyl groups of the $\mathrm{gAC}$ in addition to $(\mathrm{Si}-\mathrm{OH})$ on $\mathrm{gAC} / \mathrm{SiO}_{2}$ composite, whose surface exhibits a net negative charge at $\mathrm{pH}$ values $>\mathrm{pH}_{\mathrm{PZC}} \approx 6.8$ and 4.12 , respectively $[17,25]$. In addition, when the adsorbent dose increases, the number of sorption active surface sites will increase, as a result increasing the percentage of Astrazon removal percentage (\%R), but promotes a remarkable decrease in the amount of an Astrazon uptake per gram of adsorbent. This effect that can be mathematically explained by the expression of $q_{e}=\frac{96 \mathrm{R} \times \mathrm{C}_{g}}{100 \times \mathrm{w}}$. This equation indicate that the $q_{e}(\mu \mathrm{mol} / \mathrm{g})$ of Astrazon dye at a fixed amount of Astrazon dye is inversely proportional with the amount of adsorbent dose (w) [26]. These results clearly indicate that the adsorbents dosages must be fixed at minimum amount of $1 \mathrm{~g} / \mathrm{L}$ for the entire experiments, which is the dosage that corresponds to the minimum amount of adsorbent that leads to a maximum saturation level of all vacant surfaces active sites on the adsorbents surfaces. 

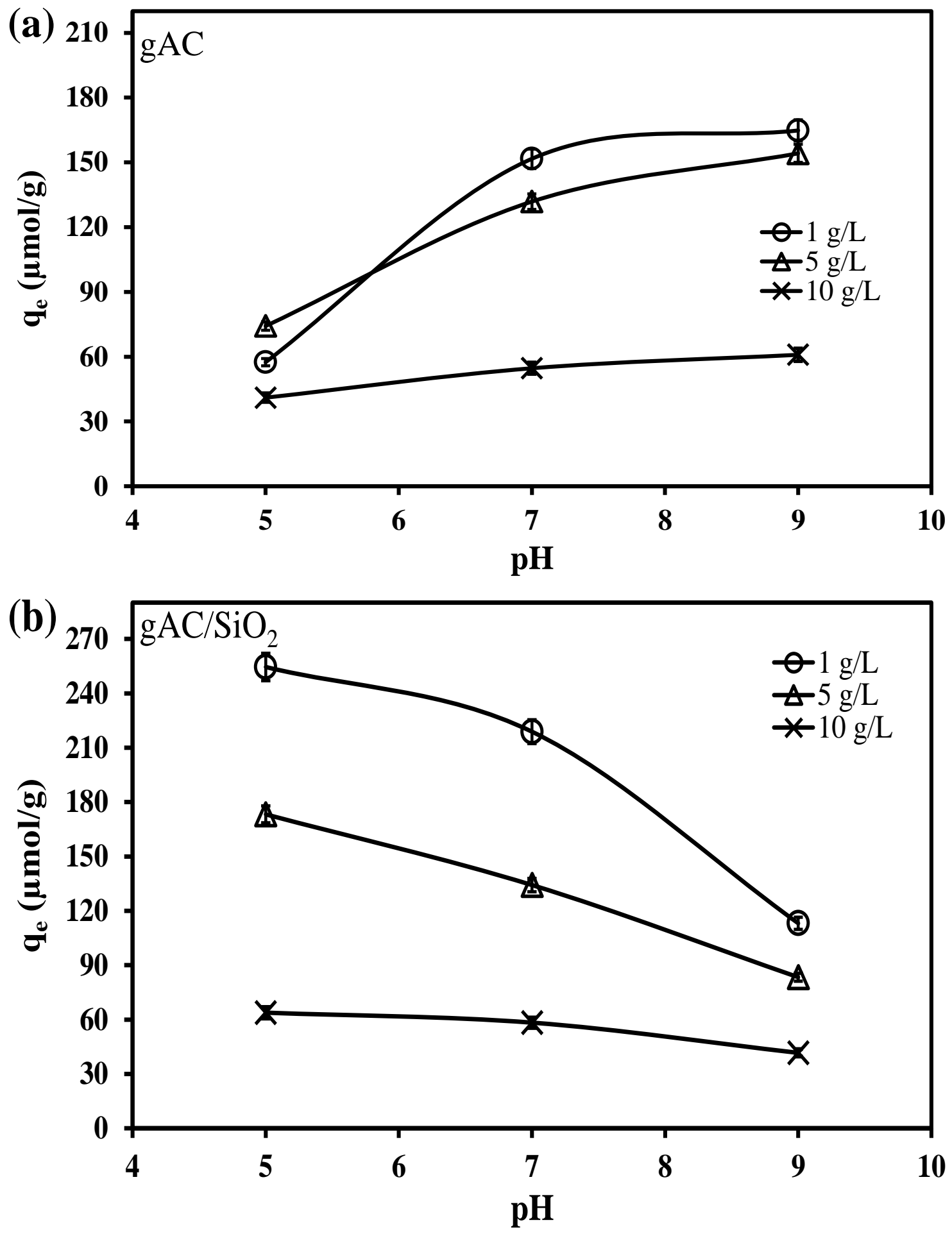

Fig. 4: Effect of $\mathrm{pH}(5-9)$ and adsorbent dose (1-10 $\mathrm{g} / \mathrm{l})$ on the adsorbed amount of astrazon dye using (a) $\mathrm{gAC}$ and (b) $\mathrm{gAC} / \mathrm{SiO}_{2}$ adsorbents.

\section{III.2. Adsorption kinetic and thermodynamic}

It is important to predict the uptake rate at which the Astrazon pink FG dye is removed from water solutions to design a case study adsorption treatment plant. In order to examine the rate of the Astrazon pink FG dye on both $\mathrm{gAC}$ and $\mathrm{gAC} / \mathrm{SiO}_{2}$ adsorbents and modeling the experimental data, three nonlinear kinetic models (Eqs. 4-6) were employed, including pseudo-first-order, pseudo-second-order, and the Elvoich kinetic equations $[27,23,22]$. The kinetic parameters of the above kinetic models were estimated from the nonlinear curve-fitting procedure of the experimental data using SPSS v. 21 software to investigate the controlling mechanism of the adsorption process. 
1. The pseudo-first-order Lagergren's model (PFOM):

$$
q_{\mathrm{t}}=q_{0}\left(1-\exp \left(\leftarrow K_{1} t\right)\right)
$$

2. The pseudo-second order model (PSOM):

$$
q_{\mathrm{t}}={ }^{K_{2} q_{0}^{2} t} / 1+K_{2} q_{0} t
$$

Where $q_{0}$ and $q_{\mathrm{t}}(\mathrm{mg} / \mathrm{g})$ are the amounts of adsorbate adsorbed at equilibrium and at any time $t(\mathrm{~h})$ respectively, $K_{1} \quad(\mathrm{~h}$ $\left.{ }^{1}\right)$ is the pseudo-first adsorption rate constant, $K_{2}\left(\mathrm{~g} /\left(\mu \mathrm{mol}{ }^{*} \mathrm{~h}\right)\right)$ is the rate constant of pseudo-second model.

3. The Elovich equation:

$$
q_{t}=\beta \ln (\alpha \beta t)
$$

Where the Elovich constants $\alpha$ and $\beta$ represent the initial adsorption rate $\left(g /\left(\mu \mathrm{mol} \mathrm{l}^{2}\right)\right)$ and the desorption constant $\left(\mu \mathrm{mol} /\left(g^{\star} h\right)\right)$, respectively.

Calculated kinetic constants and correlation coefficients for the applied kinetic models by using a nonlinear regression procedure for Astrazon adsorption onto $\mathrm{gAC}$ and $\mathrm{gAC} / \mathrm{SiO}_{2}$ sorbents at different initial dye concentrations and temperatures are tabulated in Table 1. In this work, all the calculated coefficients $\left(R^{2}\right)$ for the three kinetic models were high enough $(>0.8)$ to significantly simulate and predict the experimental adsorption data of Astrazon using gAC and $\mathrm{gAC} / \mathrm{SiO}_{2}$ sorbents. This confirmed by the low statistical nonlinear chi-square test $\left(Z^{2}\right)$ between predicted and experimental results and the fitting curvatures of kinetic equations with the experimental data, which presented in Fig. (5).

(a)

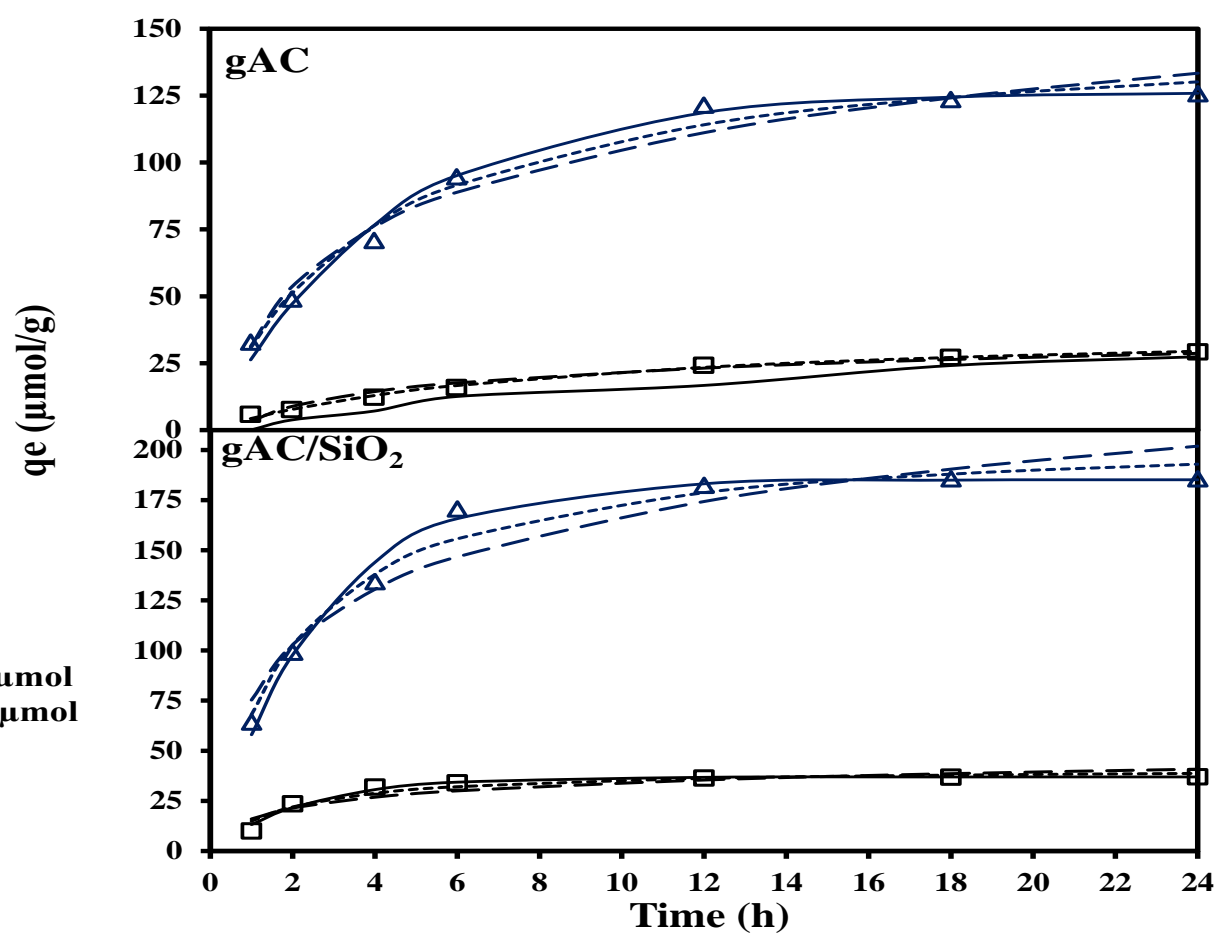


(b)

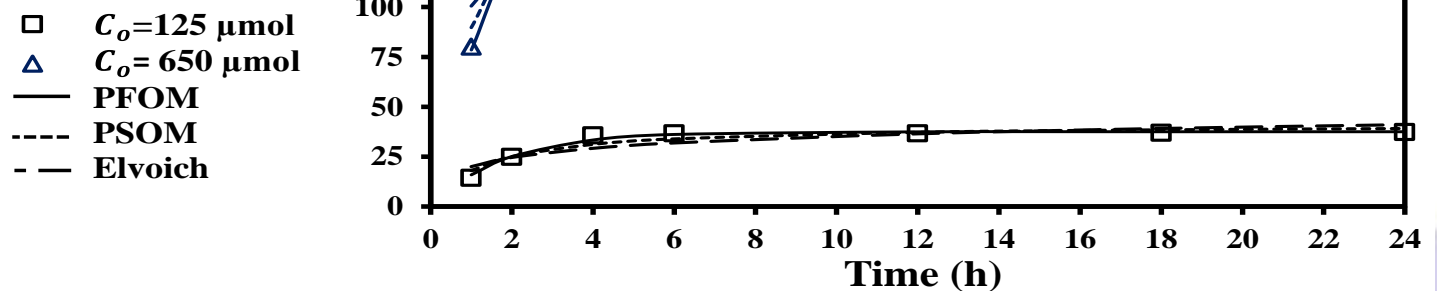

Fig. 5: Experimental and kinetic modeling of astrazon adsorption capacities $(\mu \mathrm{mol} / \mathrm{g})$ at $C_{0}$ of 125 and $650 \mu \mathrm{mol}$ using $\mathrm{gAC}$ and $\mathrm{gAc} / \mathrm{SiO}_{2}$ sorbents at (a) $298 \mathrm{~K}$ and (b) $318 \mathrm{~K}$.

The statistical $X^{2}$ error values ranged from 0.82 - 3.74 and $0.12-1.47$ for PFOM, 0.538- 1.379 and $1.873-3.189$ for $\mathrm{PSOM}$, and $0.138-2.565$ and $4.585-12.069$ for Elvoich using $\mathrm{gAC}$ and $\mathrm{gAC} / \mathrm{SiO}_{2}$ sorbents, respectively. Based on the $X^{2}$ and $R^{2}$ data in Table (1), it can be shown that the applicability of the PSOM to describe the Astrazon adsorption by $\mathrm{gAC}$ and PFOM for Astrazon adsorption by $\mathrm{gAC} / \mathrm{SiO}_{2}$ sorbent with highest calculated coefficients $\left(R^{2}>0.99\right)$ closer to unity. These obvious kinetic results were found fitted at the dye concentrations (125 and $650 \mu \mathrm{mol}$ ) and solution temperatures (298 and $318 \mathrm{~K}$ ) being studied. This observation may indicate the occurrence of a combination of both physical and chemical adsorption processes with favourable physical adsorption, which may control the adsorption rate $[3,23]$. Furthermore, the Elovich kinetic model was also used to explain the present adsorption phenomena and to understand the initial uptake rate as well as the nature of sites involved in the adsorption process for both adsorbents. In this case, it can be seen in Table 1 that the values of $\alpha$ and $\beta$ showed a general inverse correlation trend and that $1 / \beta$ (which is apparently indicative of the number of sites available for adsorption) showed a distinct decrease with increase dye concentrations with no significant values difference at the two studied temperatures values (298 and $318 \mathrm{~K})$. This again reinforcing the occurrence of a combined physicochemical adsorption for Astrazon dye adsorbate by both adsorbents. But, the above kinetic models cannot identify the diffusion mechanism and therefore the kinetic results were then subjected to analyze by the intraparticle diffusion model. The intraparticle diffusion models such as Weber and Morris (WMM) theory was further studied to determine the diffusion mechanism [22]. According to WMM theory (Eq. 7) the adsorption uptake varies proportionally with $t^{0.5}$ rather than the contact time $t$.

$$
q_{t}=K_{\text {id }} t^{0.5}+C_{i}
$$

Where $K_{\text {id }}\left(\mu \mathrm{mol} / \mathrm{g} h^{0.5}\right)$ is the rate constant of of stage $i$. If the linear curvature plots of $q_{t}$ versus $t^{0.5}$ will be passing through the origin, then the intraparticle diffusion is only the rate limiting step. Otherwise, other mechanisms are also involved along with intraparticle diffusion [27]. In the present case, the Astrazon dye diffusion curvatures consist from two linearity adsorption stages are involved in the process (Fig. 6). 


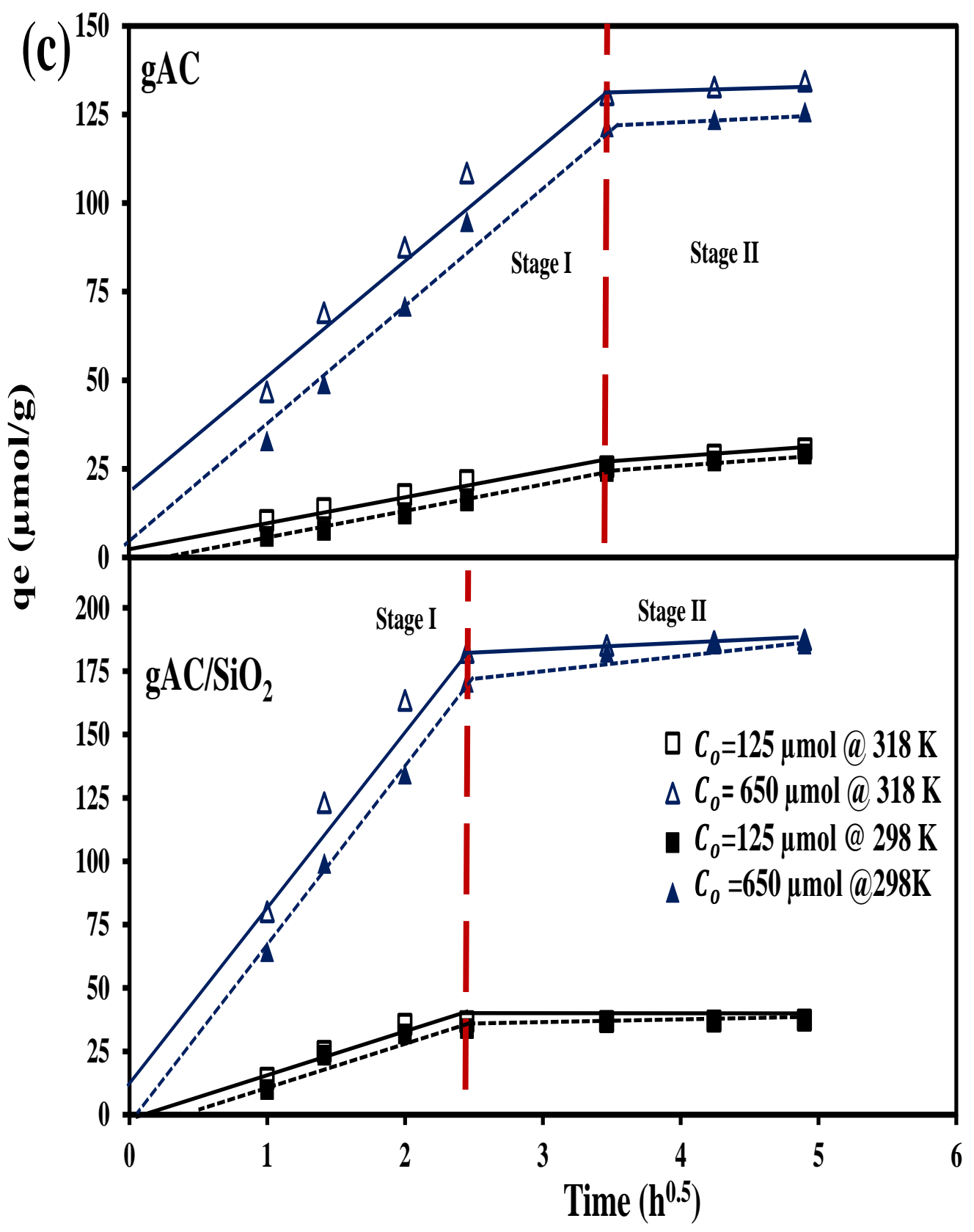

Fig. 6: Intraparticle diffusion curvatures of astrazon dye onto gAC and $\mathrm{gAC} / \mathrm{SiO}_{2}$ adsorbent based on WMM theory at $C_{o}$ of 125 and $650 \mu \mathrm{mol}$.

The first region (macro-pore diffusion phase) is the initially faster instantaneous or external surface adsorption stage, which completed within 6 to $12 \mathrm{~h}$, respectively by $\mathrm{gAC} / \mathrm{SiO}_{2}$ and $\mathrm{gAC}$ sorbents. However, the second stage (micro-pore diffusion phase) is the rate limiting intraparticle diffusion due to the equilibrium state $[27,22]$. It was also observed that the $K_{\text {id }}$ values (Table 1) were found to be higher by suing $\mathrm{gAC} / \mathrm{SiO}_{2}$ sorbent than that of using $\mathrm{gAC}$ alone, which agree with their previous adsorption affinities. In addition, it was obvious that there is a high significant increase in the $K_{\text {id }}$ with increasing initial dye concentrations by about 4 times. Also, diffusion rate constant of $K_{\text {id }}\left(\mu \mathrm{mol} \mathrm{g} \mathrm{g}^{-1} \mathrm{~h}^{0.5}\right)$ were found to be exhibiting a low significant depending on the studied temperature ranges, which confirm that the applied adsorption system is independent on temperature variable. Referring to Fig. 5, the WMM empirical relationship for adsorbed Astrazon dye adsorbate by both adsorbents stated that the intraparticle diffusion is not the rate-factor for the Astrazon adsorption. This due to the two linear curvatures stages for adsorbed Astrazon dye adsorbate by both adsorbents did not pass through the zero origin, however, the linear lines scattered around the origin [22]. This ascertained that the diffusion mechanism was not the rate limiting mechanism in the studied adsorption. 
Table 1: Kinetics constants for the adsorption of different concentrations of astrazon dye ( $C_{o}=125$ and $650 \mu \mathrm{mol}$ ) at $298 \mathrm{~K}$ and $318 \mathrm{~K}$ using $\mathrm{gAC}$ and $\mathrm{gAC} / \mathrm{SiO}_{2}$ sorbents.

\begin{tabular}{|c|c|c|c|c|c|c|c|c|c|}
\hline \multirow{3}{*}{\multicolumn{2}{|c|}{ Kinetic parameters }} & \multicolumn{4}{|c|}{ gAC } & \multicolumn{4}{|c|}{$\mathrm{gAC} / \mathrm{SiO}_{2}$} \\
\hline & & \multicolumn{2}{|c|}{$\left(C_{o}=125 \mu \mathrm{mol}\right)$} & \multicolumn{2}{|c|}{$\left(C_{o}=650 \mu \mathrm{mol}\right)$} & \multicolumn{2}{|c|}{$\left(C_{o}=125 \mu \mathrm{mol}\right)$} & \multicolumn{2}{|c|}{$\left(C_{o}=650 \mu \mathrm{mol}\right)$} \\
\hline & & $298 \mathrm{~K}$ & $318 \mathrm{~K}$ & $298 \mathrm{~K}$ & $318 \mathrm{~K}$ & $298 \mathrm{~K}$ & $318 \mathrm{~K}$ & $298 \mathrm{~K}$ & $318 \mathrm{~K}$ \\
\hline Experim & tal $q_{e}\left(\mu \mathrm{mol} . \mathrm{g}^{-1}\right)$ & 29.2 & 30.6 & 125.7 & 134.4 & 36.9 & 37.3 & 185.7 & 187.4 \\
\hline \multirow{4}{*}{ PFOM } & $q_{0}\left(\mu \mathrm{mol} . \mathrm{g}^{-1}\right)$ & 30.06 & 28.49 & $\begin{array}{c}126.33 \\
7\end{array}$ & 131.92 & 36.98 & 37.52 & 185.17 & 186.9 \\
\hline & $K_{1}\left(\mathrm{~h}^{-1}\right)$ & 0.135 & 0.278 & 0.233 & 0.327 & 0.441 & 0.552 & 0.376 & 0.545 \\
\hline & $R^{2}$ & 0.993 & 0.984 & 0.994 & 0.985 & 0.989 & 0.994 & 0.995 & 0.999 \\
\hline & $x^{2}$ & 0.821 & 1.846 & 1.958 & 3.743 & 1.285 & 0.356 & 1.470 & 0.120 \\
\hline \multirow{4}{*}{ PSOM } & $q_{0}\left(\mu \mathrm{mol} . \mathrm{g}^{-1}\right)$ & 39.65 & 33.11 & 151.49 & 150.64 & 41.62 & 41.277 & 209.67 & 205.38 \\
\hline & $K_{2}\left(\mathrm{~g} . \mu \mathrm{mol}^{-1} \cdot \mathrm{h}^{-1)}\right.$ & 0.003 & 0.01 & 0.002 & 0.003 & 0.013 & 0.019 & 0.002 & 0.004 \\
\hline & $R^{2}$ & 0.995 & 0.989 & 0.992 & 0.995 & 0.967 & 0.966 & 0.99 & 0.987 \\
\hline & $X^{2}$ & 0.538 & 0.601 & 1.379 & 0.884 & 3.189 & 1.873 & 2.146 & 2.991 \\
\hline \multirow{4}{*}{ Elovich } & $\propto c\left(g \cdot \mu \mathrm{mol}^{-1} \cdot \mathrm{h}^{-2}\right)$ & 0.19 & 0.66 & 0.082 & 0.186 & 0.996 & 3.168 & 0.166 & 0.672 \\
\hline & $\beta\left(\mu\right.$ mol. $\left.g^{-1} \cdot h^{-1}\right)$ & 7.972 & 6.54 & 32.124 & 29.234 & 7.81 & 6.596 & 39.849 & 32.576 \\
\hline & $R^{2}$ & 0.967 & 0.974 & 0.971 & 0.973 & 0.831 & 0.755 & 0.924 & 0.841 \\
\hline & $x^{2}$ & 1.939 & 0.138 & 2.565 & 1.677 & 5.735 & 4.585 & 7.392 & 12.069 \\
\hline \multirow{4}{*}{ WMM } & $K_{\text {i1 }}\left(\mu \mathrm{mol} / \mathrm{g} h^{0.5}\right)$ & 6.24 & 7.617 & 33.75 & 36.71 & 15.73 & 16.19 & 70.15 & 71.45 \\
\hline & $K_{\mathrm{i} 2}\left(\mu \mathrm{mol} / \mathrm{g} h^{0.5}\right)$ & 3.58 & 3.46 & 2.96 & 2.654 & 1.21 & 0.252 & 6.23 & 2.08 \\
\hline & $R_{1}^{2}$ & 0.974 & 0.993 & 0.973 & 0.987 & 0.92 & 0.896 & 0.994 & 0.971 \\
\hline & $R_{2}^{2}$ & 0.985 & 0.996 & 0.994 & 0.995 & 0.845 & 0.81 & 0.84 & 0.97 \\
\hline
\end{tabular}

The low significant effect of temperature levels ( 298 to $318 \mathrm{~K}$ ) above was confirmed by the calculated thermodynamic constants using the Van't Hoff formula (Eqs. 8 -9) $[27,28]$ at initial Astrazon dye concentrations of $C_{0}=125$ and $650 \mu \mathrm{mol}$.

$$
\begin{array}{ll}
\Delta G^{\circ}=-R T \ln K_{e} & \text { (Eq. 8) } \\
\ln K_{e}=\frac{\Delta s^{\circ}}{R}-\frac{\Delta H^{\circ}}{R T} & \text { (Eq. 9) }
\end{array}
$$

Where $\mathrm{T}$ is absolute temperature in Kelvin; $\mathrm{R}(8.314 \mathrm{~J} / \mathrm{mol} \mathrm{K})$ is the universal gas constant; $K_{\varepsilon}$ is the ratio of adsorbate equilibriumcapacity on adsorbent $\left(q_{\varepsilon}\right)$ to the remaining dye concentrations in solution at equilibrium $\left(C_{\varepsilon}\right) ; \Delta H^{n}$ and $\Delta S^{\circ}$ are standard enthalpy and standard entropy; $\Delta G^{\circ}$ is standard free energy. The $\Delta H^{\prime \prime}$ and $\Delta S^{\circ}$ are calculated from the slope and intercept of the linear plot of $\ln K_{e}$ versus $1 / T$.

The calculated thermodynamic constants of $\Delta H^{\circ}, \Delta S^{\circ}$, and $\Delta G^{\circ}$ for adsorption of Astrazon dye on $\mathrm{gAC}$ and $\mathrm{gAC} / \mathrm{SiO}_{2}$ sorbents are shown in Table 2. The calculated positive enthalpy changes with $\Delta H^{a} \approx 8.54$ to 7.87 and 16.6 to 12.58 $\mathrm{KJ} / \mathrm{mol}$ for adsorbed Astrazon dye at $C_{0}$ range from 125 to $650 \mu \mathrm{mol}$ using gAC and $\mathrm{gAC} / \mathrm{SiO}_{2}$ sorbents, respectively show endothermic adsorption, which is consistent with the kinetic results above. The low magnitude of calculated $\Delta H^{a}$, less than $20.9 \mathrm{~kJ} / \mathrm{mol}$, reveal that the adsorption is a physical type of the adsorbents surfaces in this study [22,28,29]. The positive entropy changes with $\Delta S^{\circ} \approx 0.04$ to 0.03 and 0.08 to $0.07 \mathrm{KJ} / \mathrm{mol} \mathrm{K}$ respectively for gAC and $\mathrm{gAC} / \mathrm{SiO}_{2}$ sorbents, show the high affinity of $\mathrm{gAC} / \mathrm{SiO}_{2}$ sorbent for Astrazon dye in aqueous solution and the increase of randomness at the 


$$
\begin{array}{r}
\text { ISSN } 2321-807 x \\
\text { Jolume } 12 \text { Number } 10 \\
\text { Journal of Advances in Chemistry }
\end{array}
$$

solid/liquid interface during adsorption process. In addition, the determined Gibb's free energy changes $\left(\Delta G^{\circ}\right)$ at 298 to $318 \mathrm{~K}$ for adsorbed Astrazon dye 288 to $328 \mathrm{~K}$, respectively onto gAC sorbent are ranges from -2.12 to $-2.88 \mathrm{KJ} / \mathrm{mol}$ and 0.11 to $-0.18 \mathrm{KJ} / \mathrm{mol}$, and onto $\mathrm{gAC} / \mathrm{SiO}_{2}$ sorbent are ranges from -0.64 to $-0.80 \mathrm{KJ} / \mathrm{mol}$ and -3.14 to $-3.71 \mathrm{KJ} / \mathrm{mol}$ at $C_{0}=125$ and $650 \mu \mathrm{mol}$, respectively. The negative values of $\Delta G^{\circ}$ suggests spontaneity and feasibility of favorable adsorption by both sorbents, and the spontaneity increase with the rise in temperature from 298 to $318 \mathrm{~K}$. This kind of low significant temperature dependence of the adsorbed dye by fabricated adsorbents reflected by the insignificant changes of $\Delta G^{\circ}$ values in accordance with increasing experimental temperature values. Moreover, it can see that the $\Delta G^{\circ}$ values increases with increase of initial Astrazon concentration from 125 to $650 \mu \mathrm{mol}$ onto $\mathrm{gAC} / \mathrm{SiO}_{2}$ only, however, the opposite trend is observable on gAC sorbent. Such obvious results indicate the high affinity of $\mathrm{gAC} / \mathrm{SiO}_{2}$ sorbent to adsorb Astrazon dye even at a higher concentration than that of gAC sorbent. Likewise, the net value of $\Delta G^{\circ}$ is between 0 and $20 \mathrm{~kJ} / \mathrm{mol}$, which is the range for physisorption [26]. This further indicated that the adsorption of the Astrazon dye onto gAC and $\mathrm{gAC} / \mathrm{SiO}_{2}$ sorbents was by physisorption.

\begin{tabular}{|c|c|c|c|c|c|}
\hline \multirow{2}{*}{\multicolumn{2}{|c|}{$\begin{array}{c}\text { Thermodynamic } \\
\text { constants }\end{array}$}} & \multicolumn{2}{|c|}{$C_{0}=125 \mu \mathrm{mol}$} & \multicolumn{2}{|c|}{$C_{o}=650 \mu \mathrm{mol}$} \\
\hline & & $g A C$ & $\mathrm{gAC} / \mathrm{SiO}_{2}$ & $g A C$ & $\mathrm{gAC} / \mathrm{SiO}_{2}$ \\
\hline \multirow{2}{*}{\multicolumn{2}{|c|}{$\begin{array}{c}\Delta H^{\circ}(\mathrm{KJ} / \mathrm{mol}) \\
\Delta S^{\circ}(\mathrm{KJ} / \mathrm{mol} \mathrm{K})\end{array}$}} & 8.54 & 16.60 & 7.87 & 12.58 \\
\hline & & 0.04 & 0.08 & 0.03 & 0.07 \\
\hline \multirow{3}{*}{$\begin{array}{c}\Delta G^{\circ} \\
(\mathrm{KJ} / \mathrm{mol})\end{array}$} & $298 K$ & -2.12 & -0.64 & -0.11 & -3.14 \\
\hline & $303 \mathrm{~K}$ & -2.44 & -0.74 & -0.14 & -3.30 \\
\hline & $318 \mathrm{~K}$ & -2.88 & -0.80 & -0.18 & -3.71 \\
\hline
\end{tabular}

\section{Table 2: Thermodynamic constants of the adsorbed astrazon dye onto $\mathrm{gAC}$ and $\mathrm{gAC} / \mathrm{SiO}_{2}$ sorbents at $C_{o}$ of 125 and $650 \mu \mathrm{mol}$.}

\section{III.3. Isotherm modeling of adsorbed Astrazon dye onto $\mathrm{gAC}$ and $\mathrm{gAC} / \mathrm{SiO}_{2}$ sorbents}

The equilibrium adsorption isotherm can provide the maximum adsorption capacity and examine the effectiveness of the prepared adsorbents. In addition, the isotherm provides information on how the Astrazon pink FG dye adsorbed onto the $\mathrm{gAC}$ and $\mathrm{gAC} / \mathrm{SiO}_{2}$ adsorbents and the commercial viability of the fabricated materials for the textile wastewater remediation. The effect of initial Astrazon dye concentrations $\left(C_{0}\right.$ of 50-1050 $\left.\mu \mathrm{mol}\right)$ on the adsorption capacity $q_{\theta}(\mu \mathrm{mol} / \mathrm{g})$ for the $\mathrm{gAC}$ and $\mathrm{gAC} / \mathrm{SiO}_{2}$ adsorbents was studied at their equilibrium times obtained above. A nonlinear regression solving of Langmuir (L), Freundlich ( $F$ ), Temkin (T), Redlich-Peterson (R-P), and Langmuir-Freundlich (L-F) isotherm models $[27,22,28,30]$ were applied to simulate the adsorbed Astrazon dye results. The Langmuir isotherm has been often applied to a homogeneous adsorption surface with adsorbent active sites having equal adsorbate affinity with a monolayer saturation of dye on the solid surfaces. Freundlich model is an empirical equation based on adsorption on a heterogeneous adsorbent surface of varied affinities, and it assumes that adsorbed dye is occupied first on the stronger binding sites. The Temkin isotherm equation assumes that the heat of adsorption of all the dye molecules in the layer decreases linearly with coverage due to adsorbent-dye interactions, and that the adsorption is characterized by a uniform distribution of the binding energies $[22,28,30,1]$. The R-P and L-F isotherm is a mix equation of Langmuir-Freundlich equations, and the R-P exponent constant $(0<b<1)$ can characterize the adsorption isotherm favorability $[29,1]$. R-P and $\mathrm{L}-\mathrm{F}$ model has two limiting cases, when exponent values equal unity, the Langmuir equation is more favorable, whereas when exponent values $=0, R-P$ equation transforms to Henry's law equation $[29,30,1]$.

The simulated nonlinear isotherm expressions for the experimental adsorbed Astrazon dye and their corresponding determination coefficients $\left(R^{2}\right)$, and the nonlinear chi-square $\left(X^{2}\right)$ error test were provided using IBM-SPSS (v. 21) and Minitab Statistics (v.17) software through nonlinear curve fitting analysis. The isotherm equilibrium models including isotherm constants, $R^{2}$ and $X^{2}$ values onto $\mathrm{gAC}$ and $\mathrm{gAC} / \mathrm{SiO}_{2}$ adsorbents are tabulated in Table 3. According to the $R^{2}$ values in Table 3, all the calculated correlation coefficients values are close to unity $(\geq 0.96)$ except for Freundlich isotherm model with $R^{2}$ of $0.88-0.87$ with the highest error $X^{2}$ analysis values $\approx 65.65-103.19$. These results indicated that Freundlish model alone showed the poorest-fitting to the experimental equilibrium data of the adsorbed Astrazon dye onto both adsorbents in this study. This because of Freundlich isotherm assumed that the adsorbed dye on the adsorbent surfaces increase with the raise of the initial dye concentrations, which is not observable in our case. This obvious in isotherm curvatures represented in Fig. (7), which shows that the adsorption capacities of Astrazon dye sharply increase to reach a plateau of maximum equilibrium trend at initial concentrations of $400 \mu \mathrm{mol}$ dye. At this concentration points, the maximum experimental $q_{e}(\mu \mathrm{mol} / \mathrm{g})$ were recorded respectively as 185.59 and 256.02 onto $\mathrm{gAC}$ and $\mathrm{gAC} / \mathrm{SiO}_{2}$ adsorbents. In addition, the magnitude of dimensionless exponent values of the R-P and L-F isotherm models are equal to unity value and ranges from 0.97 to 0.99 for R-P equation and 0.94 to 0.72 for L-F equations using gAC and gAC/SiO

4435 | P a g e 
sorbents, respectively (Table 3). The results further confirmed by the lower Freundlich exponent values below one $(1 / n$ of 0.23 and 0.15 ), which indicates a normal Langmuir isotherm. Tabulated isotherm expressions (Table 3 ) and their graphical representations in Fig. 7 showed that the Langmuir, R-P and L-F models are the preferable isotherm $\left(R^{2} \geq 0.99\right)$ for Astrazon adsorption onto both $\mathrm{gAC}$ and $\mathrm{gAc} / \mathrm{SiO}_{2}$ sorbents. Whereas based on the nonlinear chi-square error $Z^{2}$ data, the experimental adsorption equilibrium obeys the Langmuir isotherm using gAC ( $R^{2} 0.997$ and $\left.X^{2} 0.59\right)$ and LangmuirFreundlich (L-F) model using $\mathrm{gAc} \mathrm{SiO}_{2}\left(R^{2} 0.993\right.$ and $X^{2}$ 5.71). Such isotherm data shows that the $\mathrm{gAC}$ and $\mathrm{gAC}_{\mathrm{SiO}}$ characterized by a certain degree of a heterogeneity binding sites $\left(B_{T}=29.70-26.852 \mathrm{~J} / \mathrm{mol}\right)$ as revealed by the Temkin model $\left(R^{2} 0.97-0.96\right)[29,30]$.

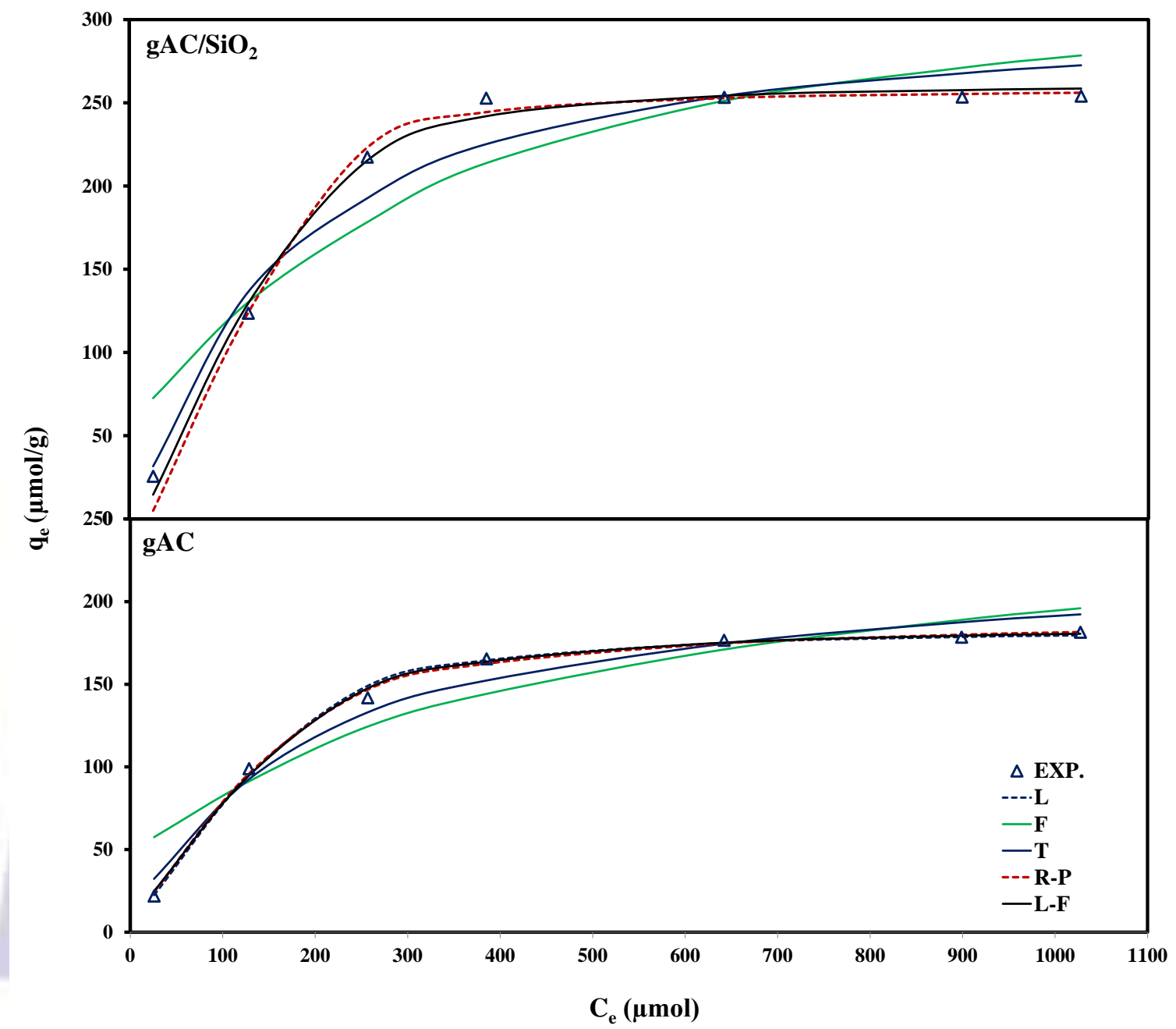

Fig. 7: Equilibrium isotherms for the adsorbed astrazon pink FG dye onto gAC and $\mathrm{gAC} / \mathrm{SiO}_{2}$ adsorbents.

But, the equilibrium binding constant corresponding to the maximum binding energy of adsorbed dye using $g A C(A=0.77$ $\mathrm{L} / \mathrm{g})$ is much lower than that of using $\mathrm{gAC} / \mathrm{SiO}_{2}(\mathrm{~A}=33.10 \mathrm{~L} / \mathrm{g})$. This result ascertain that the adsorbed Astrazon dye onto both adsorbents showed best-fitting with a Langmuir isotherm model with some heterogeneity on the $g A C / S i O_{2}$ surface due to the components of the composite structure. Comparing the dimensionless separation factor, $R_{L}$, of adsorbed dye onto both adsorbent showed that the $R_{L}$ values decreased from 0.024 onto gAC to 0.005 onto $\mathrm{gAC} / \mathrm{SiO}_{2}$ at $C_{0}$ of 1000 $\mu \mathrm{mol}$. This indicated that Astrazon dye adsorption was more favourable onto $\mathrm{gAC} / \mathrm{SiO}_{2}$ than that onto gAC sorbent and such results revealed the enhancement of adsorbent surface affinity to adsorb Astrazon dye molecules. Such conclusion further confirmed by the adsorption isotherm intensities constants of $\left(K_{\mathrm{L}}, K_{f}\right.$, and $\left.K_{\mathrm{t}}\right)$ that appear significantly higher for the adsorbed Astrazon dye onto $\mathrm{gAC} / \mathrm{SiO}_{2}$ system than $\mathrm{gAC}$ system alone. These higher values indicate greater affinity and better effectiveness for the Astrazon dye molecules on $\mathrm{gAC} / \mathrm{SiO}_{2}$ and confirming their high adsorption capacity $(\mu \mathrm{mol}$ $\mathrm{g}$ ). This is may be due to increase in the number of surface active sites related to multi-components structure of the $\mathrm{gAC} / \mathrm{SiO}_{2}$ composite that lead to increase the adsorption rate of the dye molecules on the solid surfaces. Therefore, the $\mathrm{gAC} / \mathrm{SiO}_{2}$ composite adsorbent can use for preventing the dye contamination in textile wastewater in a shorter time. 
Table 3: Adsorption isothermal models, determination coefficients, and the nonlinear chisquare $\left(X^{2}\right)$ test of adsorbed astrazon dye onto $\mathrm{gAC}$ and $\mathrm{gAC} / \mathrm{SiO}_{2}$ adsorbents.

\begin{tabular}{|c|c|c|c|c|c|c|}
\hline \multirow{2}{*}{ Isotherm models } & \multicolumn{2}{|c|}{ Adsorbents } & \multicolumn{2}{|c|}{ gAC } & \multicolumn{2}{|c|}{$\mathrm{gAC} / \mathrm{SiO}_{2}$} \\
\hline & $g A C$ & $\mathrm{gAC} / \mathrm{SiO}_{2}$ & $R^{2}$ & $X^{2}$ & $R^{2}$ & $X^{2}$ \\
\hline Langmuir (L) & $q_{e}=185.59 \frac{0.04 C_{e}}{1+0.04 C_{e}}$ & $q_{e}=256.02 \frac{0.19 C_{e}}{1+0.19 C_{e}}$ & 0.997 & 0.59 & 0.993 & 9.64 \\
\hline Freundlich $(F)$ & $\begin{array}{l}\left.D_{-}-1 / / 1 \perp \cap n \Delta \Gamma\right) \backsim \cap \cap 1 \\
q_{e}=42.22 C_{\theta}^{1 / 4.39}\end{array}$ & $\begin{array}{l}\left.D_{-}-1 / / 1+n 10 r\right)-\cap n \cap 5 \\
q_{e}=102.75 C_{e}^{1 / 6.67}\end{array}$ & 0.88 & 65.65 & 0.87 & 103.19 \\
\hline Temkin $(T)$ & $q_{e}=29.70 \ln \left(0.77 C_{e}\right)$ & $q_{e}=26.852 \ln \left(33.10 C_{e}\right)$ & 0.97 & 8.12 & 0.96 & 10.74 \\
\hline $\begin{array}{l}\text { Redlich-Peterson } \\
\text { (R-P) }\end{array}$ & $q_{e}=\frac{7.42 C_{e}}{1+0.04 C_{e}^{0.97}}$ & $q_{e}=\frac{51.45 C_{e}}{1+0.21 C_{e}^{0.99}}$ & 0.997 & 0.65 & 0.992 & 9.12 \\
\hline $\begin{array}{l}\text { Langmuir- } \\
\text { Freundlich (L-F) }\end{array}$ & $q_{e}=188.26 \frac{\left(0.034 C_{e}\right)^{0.94}}{1+\left(0.034 C_{e}\right)^{0.94}}$ & $q_{e}=265.77 \frac{\left(0.19 C_{e}\right)^{0.72}}{1+\left(0.19 C_{e}\right)^{0.72}}$ & 0.997 & 0.85 & 0.993 & 5.71 \\
\hline
\end{tabular}

\section{CONCLUSION}

The prepared granular carbon $(\mathrm{gAC})$ and granular carbon-silica aerogels composite $\left(\mathrm{gAC} / \mathrm{SiO} \mathrm{O}_{2}\right)$ adsorbents proved to be a successful adsorbing material for Astrazon pink FG dye from wastewater solutions in batch system. The adsorption results by each adsorbent were found to be highly influenced by contact time, the $\mathrm{pH}$ solution, and initial dye concentrations, however, temperature showed a low significant effect on the dye adsorption capacity. The maximum uptake of the Astrazon dye by the prepared $\mathrm{gAC}$ and $\mathrm{gAC} / \mathrm{SiO}_{2}$ was attained at $\mathrm{pH} 5-7$, adsorbent dose of $1 \mathrm{~g} / \mathrm{l}$, and a temperature of $318 \mathrm{~K}$ and adsorption capacities increased with increasing initial dye concentrations up to $400 \mu$ mol. The adsorption kinetics were better described by both pseudo-second-order (PSOM) and pseudo-first-order (PFOM) kinetic models respectively when using $\mathrm{gAC}$ and $\mathrm{gAC} / \mathrm{SiO}_{2}$ adsorbents, while the intraparticle diffusion was not the only rate controlling step of the adsorption process. Based on the calculated nonlinear chi-square error test and determination coefficient values using IBM-SPSS (v.21) and MINITAB (v.17) software, the mathematical isotherm description of the adsorbed Astrazon dye can be ranked as Langmuir $>$ Redlich-Peterson (R-P) > Langmuir- Freundlich > Temkin > Freundlich when using $\mathrm{gAC}$ sorbent. Whereas by using $\mathrm{gAC} / \mathrm{SiO}_{2}$ sorbent the mathematical isotherm to predict the adsorption equilibrium capacity can be rearranged in the order of Langmuir-Freundlich $>$ Redlich-Peterson $>$ Langmuir $>$ Temkin $>$ Freundlich. The equilibrium adsorption data of Astrazon dye onto the $\mathrm{gAC} / \mathrm{SiO}_{2}$ composite was found to exhibit non-linear favorable adsorption onto heterogeneous surfaces that could well be characterized by the Langmuir- Freundlich isotherm model, indicating monolayer adsorption on a heterogeneous surface and the adsorption capacity. The maximum dye adsorption capacities were found to be 185.6 and $256.02 \mu \mathrm{mol} / \mathrm{g}$ onto $\mathrm{gAC}$ and $\mathrm{gAC} / \mathrm{SiO}_{2}$ adsorbents, respectively within the studied constrains levels. The description of adsorbed Astrazon dye onto $\mathrm{gAC}$ and $\mathrm{gAC} / \mathrm{SiO}_{2}$ according to the calculated thermodynamic constants is that the adsorption systems have physical endothermic nature with the increase disorder at the solid/liquid interface during adsorption due to the low positive value of $\Delta \mathrm{S}^{\circ}$ and $\Delta \mathrm{H}^{\circ}<20 \mathrm{KJ} / \mathrm{mol}$. While, the negative values of $\Delta G^{\circ}$ obtained indicated the spontaneous nature of the adsorption process within the experiment temperatures. Finally, since palm-date pits that are used in this management study is a natural solid waste material discharged from food industries is free, abundant and locally available. So, this prepared $\mathrm{gAC} / \mathrm{SiO}_{2}$ aerogel composite is expected to be economically viable for textile wastewater purification.

\section{REFERENCES}

[1] M.F. Elkady, A.M. Ibrahim, M.M. Abd El-Latif, Assessment of the adsorption kinetics , equilibrium and thermodynamic for the potential removal of reactive red dye using eggshell biocomposite beads, Desalination, 278 (2011) 412-423. doi:10.1016/j.desal.2011.05.063.

[2] A. Duta, M. Visa, Simultaneous removal of two industrial dyes by adsorption and photocatalysis on a fly-ash - $\mathrm{TiO}_{2}$ composite, J. Photochem.and Photobiol. A: Chem. 306 (2015) 21-30. doi:10.1016/j.jphotochem.2015.03.007.

[3] Y.R. Zhang, S.L. Shen, S.Q. Wang, J. Huang, P. Su, Q.R. Wang, B.X. Zhao, A dual function magnetic nanomaterial modified with lysine for removal of organic dyes from water solution, Chem. Eng. J. 239 (2014) $250-256$.

4437 | $\mathrm{P}$ a g e 
[4] W. Zhu, X. Yang, Y. Li, J. Li, D. Wu, Y. Gao, F. Yi, A novel porous molybdophosphate-based Fe II , III -MOF showing selective dye degradation as a recyclable photocatalyst, Inorg. Chem. Commun. 49 (2014) 159-162. doi:10.1016/j.inoche.2014.09.033.

[5] F. Lian, G. Cui, Z. Liu, L. Duo, G. Zhang, B. Xing, One-step synthesis of a novel N-doped microporous biochar derived from crop straws with high dye adsorption capacity, J. Environ. Manage. 176 (2016) 61-68.

[6] M. Khairy, W. Zakaria, Effect of metal-doping of $\mathrm{TiO}_{2}$ nanoparticles on their photocatalytic activities toward removal of organic dyes, Egypt. J. Pet. 23 (2014) 419-426. doi:10.1016/j.ejpe.2014.09.010.

[7] J.M. Rosa, A.M.F. Fileti, E.B. Tambourgi, Dyeing of cotton with reactive dyestuffs: the continuous reuse of textile wastewater effluent treated by Ultraviolet/ Hydrogen peroxide homogeneous photocatalysis, J. Clean. Prod. 90 (2015) 60-65. doi:10.1016/j.jclepro.2014.11.043.

[8] B. Heibati, S. Rodriguez-Couto, M.A. Al-Ghouti, M. Asif, I. Tyagi, S. Agarwal, V. Gupta, Kinetics and thermodynamics of enhanced adsorption of the dye AR 18 using activated carbons prepared from walnut and poplar woods, J. Mol. Liq. 208 (2015) 99-105.

[9] J.O. Babalola, B.A. Koiki, Y. Eniayewu, A. Salimonu, J.O. Olowoyo, V.O. Oninla, H.A. Alabi, A. E. Ofomaja, M.O. Omorogie, Adsorption efficacy of Cedrela odorata seed waste for dyes: Non linear fractal kinetics and non linear equilibrium studies, J. Environ. Chem. Eng. 4 (2016) 3527-3536.

[10] F. Zietzschmann, C. Stützer, M. Jekel, Granular activated carbon adsorption of organic micro-pollutants in drinking water and treated wastewater-Aligning breakthrough curves and capacities, Water Res. 92 (2016) 180-187. doi:10.1016/j.watres.2016.01.056.

[11] G. Qin, Y. Yao, W. Wei, T. Zhang, Preparation of hydrophobic granular silica aerogels and adsorption of phenol from water, Appl. Surf. Sci. 280 (2013) 806-811. doi:10.1016/j.apsusc.2013.05.066.

[12] R. H. Hesas, A. A, Niya, W. M, A. W. Dauda, J.N. Sahu, Preparation of granular activated carbon from oil palm shell by microwave-induced chemical activation: Optimisation using surface response methodology, Chem. Eng. Res. Des. 91 (2013) 2447-2456. doi:10.1016/j.cherd.2013.06.004.

[13] H.H. Salih, C.L. Patterson, G.A. Sorial, R. Sinha, R. Krishnan, The fate and transport of the $\mathrm{SiO}_{2}$ nanoparticles in a granular activated carbon bed and their impact on the removal of VOCs, J. Hazard. Mater. 193 (2011) 95-101. doi:10.1016/j.jhazmat.2011.07.030.

[14] C. Djilani, R. Zaghdoudi, F. Djazi, B. Bouchekima, A. Lallam, A. Modarressi, M. Rogalski, Adsorption of dyes on activated carbon prepared from apricot stones and commercial activated carbon, J. Taiwan Inst. Chem. Eng. 53 (2015) 112-121.

[15] Y. Gokce, Z. Aktas, Nitric acid modification of activated carbon produced from waste tea and adsorption of methylene blue and phenol, Appl. Surf. Sci. 313 (2014) 352-358. doi:10.1016/j.apsusc.2014.05.214.

[16] G. Tzvetkov, S. Mihaylova, K. Stoitchkova, P. Tzvetkov, T. Spassov, Mechanochemical and chemical activation of lignocellulosic material to prepare powdered activated carbons for adsorption applications, Powder Technol. 299 (2016) 41-50. doi:10.1016/j.powtec.2016.05.033.

[17] N. Saad, M. Al-Mawla, E. Moubarak, M. Al-Ghoul, H. El-Rassy, Surface-functionalized silica aerogels and alcogels for methylene blue adsorption, RSC Adv. 5 (2015) 6111-6122. doi:10.1039/C4RA15504A.

[18] J. Zhu, J. Xie, X. Lü, D. Jiang, Synthesis and characterization of superhydrophobic silica and silica / titania aerogels by sol - gel method at ambient pressure, Colloids Surfaces A: Physicochem. Eng. Asp. 342 (2009) 97-101. doi:10.1016/j.colsurfa.2009.04.016.

[19] F. Shi, L. Wang, J. Liu, Synthesis and characterization of silica aerogels by a novel fast ambient pressure drying process, Mater. Lett. 60 (2006) 3718-3722. doi.org/10.1016/j.matlet.2006.03.095

[20] S.-W. Hwang, H.-H. Jung, S.-H. Hyun, Y.-S. Ahn, Effective preparation of crack-free silica aerogels via ambient drying, J. Sol-Gel Sci. Technol. 41 (2007) 139-146. DOI: 10.1007/s10971-006-0513-y

[21] S. He, Z. Li, X. Shi, H. Yang, L. Gong, X. Cheng, Rapid synthesis of sodium silicate based hydrophobic silica aerogel granules with large surface area, Adv. Powder Technol. 26 (2015) 537-541. doi:10.1016/j.apt.2015.01.002.

[22] S.A. Younis, A. Abd-Elazizc, A.I. Hashem, Utilization of a pyrrole derivative based antimicrobial functionality impregnated onto $\mathrm{CaO} / \mathrm{g}-\mathrm{C}_{3} \mathrm{~N}_{4}$ for dyes adsorption, RSC Adv.6 (2016) 89367-89379. doi: 10.1039/C6RA10143G.

[23] M. Doğan, Y. Özdemir, M. Alkan, Adsorption kinetics and mechanism of cationic methyl violet and methylene blue dyes onto sepiolite, Dye. Pigment. 75 (2007) 701-713. doi:10.1016/j.dyepig.2006.07.023.

[24] L. Zhou, S. Pan, X. Chen, Y. Zhao, B. Zou, M. Jin, Kinetics and thermodynamics studies of pentachlorophenol adsorption on covalently functionalized $\mathrm{Fe}_{3} \mathrm{O}_{4}$ at $\mathrm{SiO}_{2}-\mathrm{MWCNTs}$ core-shell magnetic microspheres, Chem. Eng. J. 257 (2014) 10-19. doi:10.1016/j.cej.2014.07.060. 
[25] M. Visa, C. Bogatu, A. Duta, Simultaneous adsorption of dyes and heavy metals from multicomponent solutions using fly ash, Appl. Surf. Sci. 256 (2010) 5486-5491. doi:10.1016/j.apsusc.2009.12.145.

[26] O. Abdelwahab, N. K. Amin, Adsorption of phenol from aqueous solutions by Luffa cylindrica fibers: Kinetics , isotherm and thermodynamic studies, Egypt. J. Aquat. Res. 39 (2013) 215-223. doi:10.1016/j.ejar.2013.12.011.

[27] S.A. Younis, Y.M. Moustafa, Synthesis of urea-modified $\mathrm{MnFe}_{2} \mathrm{O}_{4}$ for aromatic micro- pollutants adsorption from wastewater: Mechanism and modeling, Clean Technol. Environ. Policy. (2016), 1-14.. doi:10.1007/s10098-0161244-6.

[28] S.A. Younis, N.S. El-Gendy, W.I. El-Azab, Y.M. Moustafa, A.I. Hashem, The Biosorption of Phenol from Petroleum Refinery Wastewater Using Spent Waste Biomass, Energy Sources, Part A: Recover. Util. Environ. Eff. 36 (2014) 2566-2578.

[29] B. Tanhaei, A. Ayati, M. Lahtinen, M. Sillanpää, Preparation and characterization of a novel chitosan/ $/ \mathrm{Al}_{2} \mathrm{O}_{3} / \mathrm{magnetite}$ nanoparticles composite adsorbent for kinetic, thermodynamic and isotherm studies of Methyl Orange adsorption, Chem. Eng. J. 259 (2015) 1-10.

[30] M. Arshadi, F.S. Vahid, J.W.L. Salvacion, M. Soleymanzadeh, A practical organometallic decorated nano-size $\mathrm{SiO}_{2}-$ $\mathrm{Al}_{2} \mathrm{O}_{3}$ mixed-oxides for methyl orange removal from aqueous solution, Appl. Surf. Sci. 280 (2013) 726-736. 